\title{
Passive control of the bed micro-environment by using naturally ventilated mattress
}

\author{
Tereza Snášelová ${ }^{1}$, Mariya Petrova Bivolarova $^{1}$, and Arsen Krikor Melikov ${ }^{1 *}$ \\ ${ }^{1}$ International Centre for Indoor Environment and Energy, Department of Civil Engineering, Technical University of Denmark, Kgs. \\ Lyngby, Denmark
}

\begin{abstract}
Proper sleep is of a big importance considering that people spend one third of their lives sleeping. Thermal conditions and indoor air quality have an impact on sleep and thus must be optimized and controlled to enhance sleep quality. However, changing the thermal environment in the whole bedroom is not efficient, because of unnecessary use of energy and slow response of the HVAC system. Control of the bed microclimate is a quick and efficient way to obtain optimal conditions. Passive methods of control may, in a simple and inexpensive way, create comfortable and beneficial conditions for sleep. The performance of a porous mattress from highly-breathable material was investigated to validate the hypothesis that the natural ventilation it generates improves thermal and humidity conditions in bed. A simple method using a wet cloth was used to simulate sweating on the surface of a thermal manikin resembling a person in bed. The results showed promising effect of the breathable material on improving thermal and humidity conditions in bed, especially when it was used without textile cover. However, the mattress together with its original textile cover did not provide any significant ventilation effect, neither on humidity conditions in the bed, nor on cooling of the manikin's body.
\end{abstract}

\section{Introduction}

People spend around one third of a day sleeping and sleep quality has an impact on their health, performance and well-being. Thus, sleep has been an objective of research. In order to investigate the process, the different physiological signs during sleep stages and the conditions affecting sleep quality are measured.

Among other factors, indoor environment also impacts the sleep quality. Human body thermoregulation is affected by the circadian rhythm and is strongly connected to sleep regulation. While core body temperature drops during sleep, mean skin temperature rises. Slightly lower ambient temperatures might be more suitable for a good sleep, especially while using beddings.

Indoor climate standards specify proper indoor thermal environment only for awake state but not during sleep. Thermally comfortable conditions for sleeping have been the subject matter of numerous studies [1-6]. Study of appropriate indoor operative temperature and bed microclimate temperature around the human body showed a nearly-linear relationship between those two variables [2]. A comfortable bed micro-climate temperature of $30{ }^{\circ} \mathrm{C}$ turned out to be in the thermal comfort range of $-0,5 \leq \mathrm{PMV} \leq+0,5$ [2]. The effect of changing room temperature during the night on sleep was an objective of several studies [3,5]. Various conditions comprised constant ambient temperature and temperature change in patterns of rise-fall and fall-rise, while relative humidity stayed the same or changed with the ambient air temperature. The subjects reported poorer sleep quality and took longer to fall asleep in the rise-fall condition than in the other conditions [3]. Another study showed increased wakefulness and decreased percentage of REM (Rapid Eye Movement) stage and sleep efficiency index comparing rise-fall and fall-rise conditions to a constant condition of $26^{\circ} \mathrm{C}[5]$.

It is important to mention that the study conditions of the reported research related to the impact of thermal environment on sleep vary substantially. Variables, such as use of bedding, sleepwear, or ambient temperature differ a lot and this makes the comparison of the reported results fairly complicated. Therefore, sufficient information for designing an ideal sleep environment have not been acquired.

The current approach to indoor environment control comprises total volume ventilation and/or room temperature control. These methods are energy demanding and slow responding. For these reasons, there have been studies focusing on different methods for generating and controlling the bed micro-environment $[7,8]$. It is important to note that providing a suitable bed micro-environment needs to be controlled according to actual sleep comfort and this control must be completely automatic; non-automatic control clearly contradicts with the aim of providing good sleep quality.

Depending on the season, local heating or cooling by active control of the bed micro-environment would be advantageous for providing better sleep conditions. Radiant heaters, electric footwear or electric blankets and

\footnotetext{
${ }^{*}$ Corresponding author: akm@byg.dtu.dk
} 
pillows are just some of the devices used for local heating. Local heating or cooling can be also provided by warm or cool air. Air can be blown to control head surroundings, i.e. uncovered body parts, or to the feet area. Direction of such flow has an impact on perceived comfort, although this effect changes with body posture [9].

Combinations of several active measures to control the bed micro-environment were studied, in order to verify their positive effect on patients' comfort and overall energy use in hospitals [8]. The study considered measures such as electric radiant heater, electric blanket and pillow, personalized ventilation, bed ventilation or water-cooled mattress. Results showed that the local heating or cooling methods improve the bed microenvironment and would provide patients in hospitals with thermal comfort at indoor air temperature in a wider range than that recommended in the standards [8]. Some devices, such as mechanically ventilated mattresses, could provide in addition better air quality [10].

One of the easiest ways to passively control thermal comfort perceived in bed is to adjust bedding to an appropriate level. There are numerous types of covers and quilts on the market, offering different levels of thermal insulation. Thickness, weight and type of material have an impact on thermal insulation of quilts.

A use of a naturally-ventilated mattress can be a passive way to control the bed thermal environment. Such a mattress consists of highly breathable, porous, or meshed material that allows natural air movement throughout the mattress and positively affects the bed micro-environment under the quilt. Natural ventilation in this case is a result of buoyancy forces and the "pumping" effect of the in-bed body movement. This solution must be facilitated by use of a suitable bed frame and no storage space under the bed. Such a natural ventilation can provide partial cooling of the bed micro-climate and help remove excessive humidity due to perspiration. The performance of a porous mattress from highly-breathable material was investigated to validate the hypothesis that the natural ventilation it generates will improve thermal and humidity conditions in the bed. Some of the obtained results are reported in this paper.

\section{Method}

\subsection{Experimental setup}

Measurements were performed in a climate chamber with dimensions $6,0 \mathrm{~m} \times 4,7 \mathrm{~m} \times 2,5 \mathrm{~m}$. Air was supplied through the floor area and exhaust air was taken away through openings in the ceiling. For the purpose of this study, the area of the floor underneath the bed was blocked by a plastic foil to prevent any possible impact of the supplied air on the investigated natural ventilation effect of the mattress.

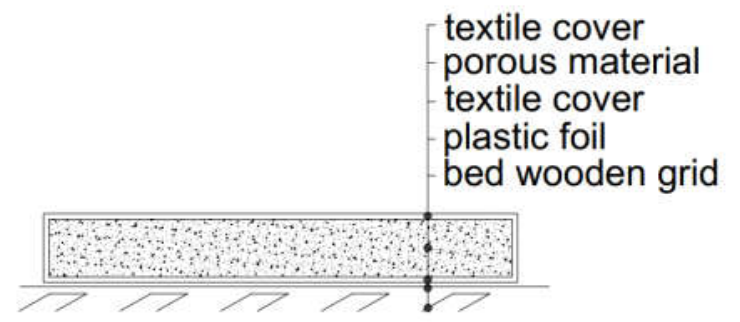

Fig. 1. Schema of the mattress set up

The mattress was made out of a highly-porous mesh of plastic fibres enclosed in a textile cover. Total thickness of the mattress was $50 \mathrm{~mm}$, with dimensions $90 \times 200 \mathrm{~cm}$. The mattress was placed in the middle of a bed frame of a size of normal queen-size bed, directly on its wooden grid, see Figure 1. No plate was placed under the mattress in order not to block the possible natural air movement. The porous mattress was by default not covered by any additional bed sheet.

A thermal manikin simulated a sleeping person under a quilt, with its head supported by a pillow. The thermal

Table 1. Experimental conditions and list of various cases

\begin{tabular}{|c|c|c|c|}
\hline No. & Conditions & $t_{a}\left({ }^{\circ} \mathrm{C}\right)$ & Mattress conditions \\
\hline $\begin{array}{l}1 \\
2 \\
3\end{array}$ & & $20^{\circ} \mathrm{C}$ & $\begin{array}{l}\text { ventilated (no plastic foil present) } \\
\text { not ventilated - foil on top of the mattress } \\
\text { not ventilated - foil below the mattress }\end{array}$ \\
\hline $\begin{array}{l}4 \\
5 \\
6 \\
7 \\
8\end{array}$ & dry & $25^{\circ} \mathrm{C}$ & $\begin{array}{l}\text { ventilated (no plastic foil present) } \\
\text { not ventilated - foil on top of the mattress } \\
\text { not ventilated - foil below the mattress } \\
\text { ventilated (no plastic foil present), without textile cover } \\
\text { not ventilated - foil below, without textile cover }\end{array}$ \\
\hline $\begin{array}{l}9 \\
10 \\
11 \\
12\end{array}$ & wet & $25^{\circ} \mathrm{C}$ & $\begin{array}{l}\text { ventilated (no plastic foil present) } \\
\text { not ventilated - foil below the mattress } \\
\text { ventilated (no plastic foil present), without textile cover } \\
\text { ventilated (no plastic foil present), without textile cover, with a bed sheet }\end{array}$ \\
\hline $\begin{array}{l}13 \\
14\end{array}$ & & $28^{\circ} \mathrm{C}$ & $\begin{array}{l}\text { ventilated } \\
\text { not ventilated - foil below the mattress }\end{array}$ \\
\hline
\end{tabular}


manikin had a realistic female body shape with 1,68 m height, divided into 23 body segments. The manikin was naked; no sleep-wear was used for the purpose of the study. The body segments of the manikin were kept at constant body surface temperature of $35^{\circ} \mathrm{C}$, except for the feet and hands, that were set to $31^{\circ} \mathrm{C}$ [11]. The manikin was tightly covered with a quilt, without any unnecessary gaps. Natural quilt with weight of $600 \mathrm{~g}$ and filling consisting of $90 \%$ Muscovy down and $10 \%$ small feathers was used in all cases.

\subsection{Experimental conditions}

To see possible effects of the porous mattress under different air temperatures, the measurements were carried out with ambient air temperature of $20{ }^{\circ} \mathrm{C}, 25{ }^{\circ} \mathrm{C}$ and $28{ }^{\circ} \mathrm{C}$. At $25^{\circ} \mathrm{C}$ and $28{ }^{\circ} \mathrm{C}$, sweating (referred as wet conditions) was simulated by the method described in the next sub-section. Relative humidity (RH) in the chamber was registered, but not controlled, staying in a range of $15-30 \%$.

A plastic foil placed below the mattress was used to block possible ventilation through the mattress and simulate a not naturally ventilated mattress. Comparison with any other common type of mattress would not be correct, because of different parameters, such as thickness, stiffness, textile cover or even possible air flowing through. Using a plastic foil simply ensured comparability, while the foil prevented air flowing through the mattress, i.e. converting it into a nonventilated mattress. The overview of the studied cases is shown in Table 1. Schema of the mattress with its textile cover and plastic foil placed underneath is shown in Figure 1.

Dry cases, i.e. without sweat simulation, were carried out under eight different conditions (Table 1, conditions 1-8). Conditions with ventilated and not ventilated mattress without the textile cover (Table 1, conditions 7 and 8) were performed to investigate an impact of the cover on cooling of the back segment.

Wet cases were performed under ambient air temperatures of $25^{\circ} \mathrm{C}$ and $28^{\circ} \mathrm{C}$, when people are expected to sweat. The condition of not ventilated mattress was simulated with the plastic foil placed below the mattress. Plastic foil placed on top of the mattress was not an applicable condition, because the foil would block any mass transfer. To verify an effect of the pure porous structure, wet condition without the textile cover was included.

\subsection{Procedure}

Temperature and relative humidity sensors were placed under the quilt, surrounding the manikin and under the back of the manikin to investigate the micro-climate in the bed, provided by the porous mattress. See the arrangement in Figure 2.

Air temperature under the quilt was measured by platinum resistance temperature detectors PT100, class A with accuracy of $\pm 0,2{ }^{\circ} \mathrm{C}$. The temperature sensors were protected by simple spherical wire structures, that kept the sensors in the space without touching any surrounding surface. The measured data were collected by Agilent data logger 34972A. Relative humidity under the back of the manikin was measured by Sensirion digital humidity sensors SHT31, with accuracy of $2 \%$ [12]. To forfend the $\mathrm{RH}$ sensors from water, perforated plastic tubes were used to cover them. Those plastic tubes were changed after every measurement under the wet conditions, because of moisture built up inside.

The following data were measured during the measurements: air temperature and relative humidity in the space under the quilt, and heat power supplied to the thermal manikin. Five measuring points around the manikin were used to monitor the bed micro-climate: right side, left side, between thighs, between ankles and under lower back, as shown in Figure 2.

Dry case measurements took approximately 30 minutes after adjusting the conditions and reaching steady state. The thermal manikin was not a sweating manikin and it provided only dry heat. Thus, a simple method with a wet cotton cloth was used to simulate wet conditions, imitating sweating of a human body in bed. A piece of cloth, of the same size as the back segment, was soaked into warm distilled water of $37^{\circ} \mathrm{C}$ and wrung to reach certain weight. The water temperature was kept slightly higher than the surface temperature of the manikin, considering a temperature decrease during the process of adjusting the weight and placing below the thermal manikin. During all wet cases, the wet cloth was always adjusted to the same weight, measured by a sensitive scale. After adjusting the weight, the cloth was placed under the back of the manikin, directly on the mattress. The RH sensors with their protection were attached to the manikin's back. Measurements of wet cases took 4 hours, in order to show the transient process when water evaporates from the cloth.

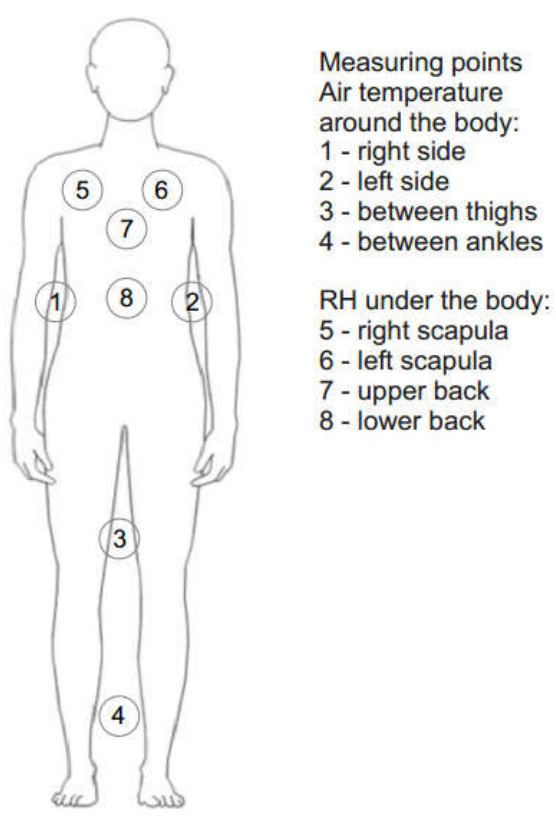

Fig. 2. Arrangement of measuring points in bed micro-climate. 

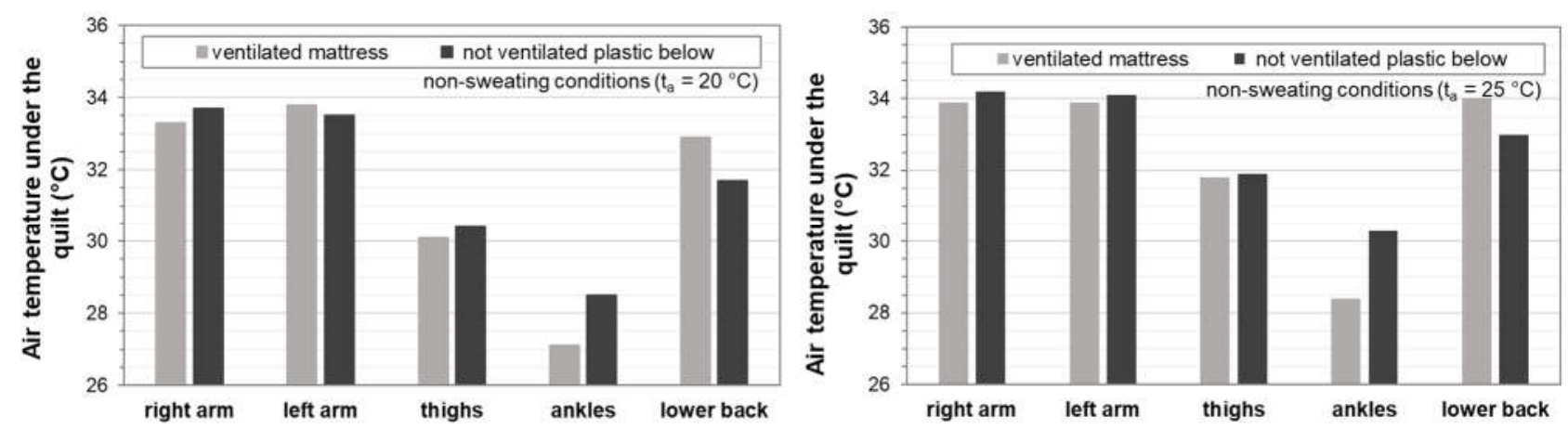

Fig.3. Air temperature under the quilt. Non-sweating conditions, $t_{a}=20^{\circ} \mathrm{C}$ and $t_{a}=25^{\circ} \mathrm{C}$.

\section{Results}

\subsection{Dry (non-sweating) condition}

Non-sweating conditions were studied under $t_{a}$ of $20^{\circ} \mathrm{C}$ and $25{ }^{\circ} \mathrm{C}$. The comparison of the results in Figure 3 showed relatively minor differences in the measured bed in the cases of ventilated and not ventilated mattress. All values were in a small range, with a maximum difference of $1,9{ }^{\circ} \mathrm{C}$. Maximal difference for ankles was $5 \%$ and $7 \%$ at $t_{a}$ of $20{ }^{\circ} \mathrm{C}$ and $25{ }^{\circ} \mathrm{C}$, respectively. The lowest values appearing around ankles could be caused by bigger distance of the sensor from the manikin, bigger air gap surrounding these body parts, and possible air leakage between the mattress and the quilt.

Readings of the heat power supply to the segments of the thermal manikin indicated cooling, especially at its back parts. Results in Figure 4a showed that for dry conditions there was no big trend of cooling, when comparing ventilated and not ventilated mattress, not even for back parts of the body. The measured data for crown and face were not considered in the comparison, because they were fully exposed to the ambient air and thus the mattress type had no impact on them. The average values of the whole manikin's heat loss, except the head, did not prove any essential difference. The difference was $2 \%$ and $4 \%$ at $t_{a}$ of $20^{\circ} \mathrm{C}$ and $25^{\circ} \mathrm{C}$, respectively. Therefore, the study was later focused more on investigation of sweating conditions.

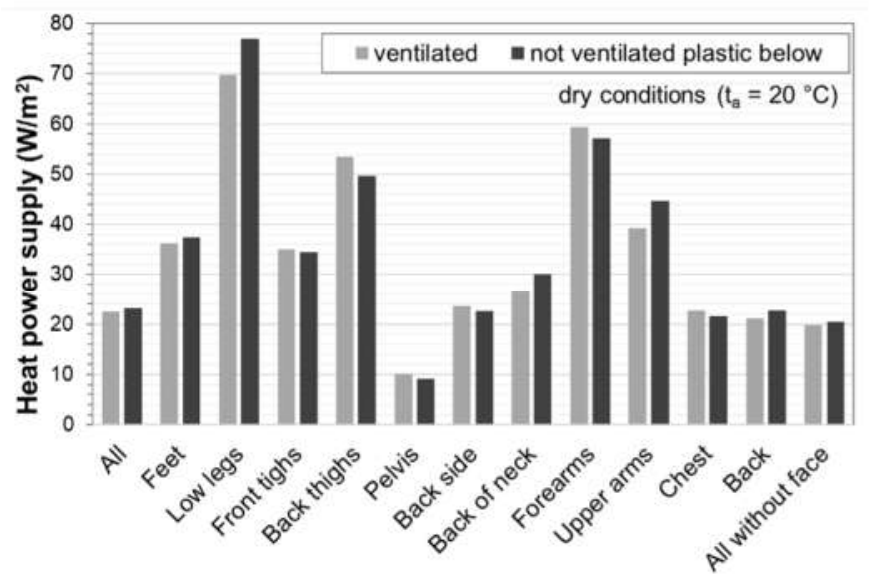

\subsection{Wet (sweating) conditions}

The sweating conditions were studied under $t_{a}$ of $25^{\circ} \mathrm{C}$ and $28{ }^{\circ} \mathrm{C}$, and each measurement took 4 hours. The air temperature under the quilt $\left(t_{a g}\right)$, i.e. air gap temperature tag for wet conditions was monitored by 4 sensors surrounding the manikin.

At $t_{a}$ of $25{ }^{\circ} \mathrm{C}, 3$ mattress conditions were investigated, see Table 1. From Figure $5 \mathrm{a}$ it is obvious that the ventilated mattress without the textile cover provided lower $t_{a g}$. During the first 15 to 30 minutes $t_{a g}$ stabilized to a certain level. This was caused by short uncovering of the manikin in the beginning of each case, when the wet cloth was placed under the manikin's back. After this initial stage, $t_{a g}$ kept slowly rising to almost steady-state level. The mattress without textile cover clearly provided lower temperature in the bed micro-environment, although the difference was about $1^{\circ} \mathrm{C}$. The results showed no considerable difference between ventilated and not ventilated mattress when the textile cover was included.

For $t_{a g}$ obtained at $t_{a}$ of $28{ }^{\circ} \mathrm{C}$, the initial temperature increase was not that significant, which is caused by higher $t_{a}$. The difference between ventilated and not ventilated mattress was smaller than at $25^{\circ} \mathrm{C}$.

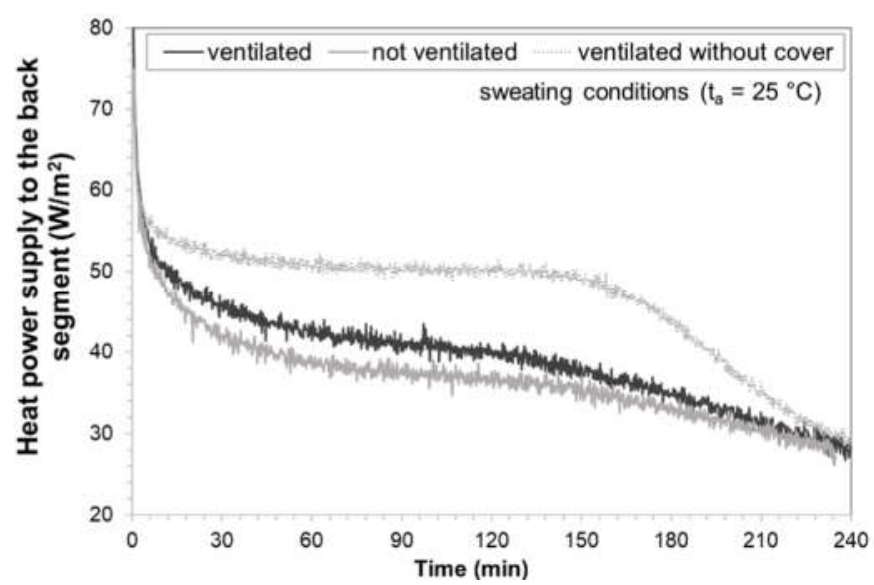

Fig. 4. a) Heat power supply to the thermal manikin under different mattress condition, $t_{a}=20^{\circ} \mathrm{C}$. b) Average $P_{m b}$ for 3 mattress conditions, $t_{a}=25^{\circ} \mathrm{C}$. 

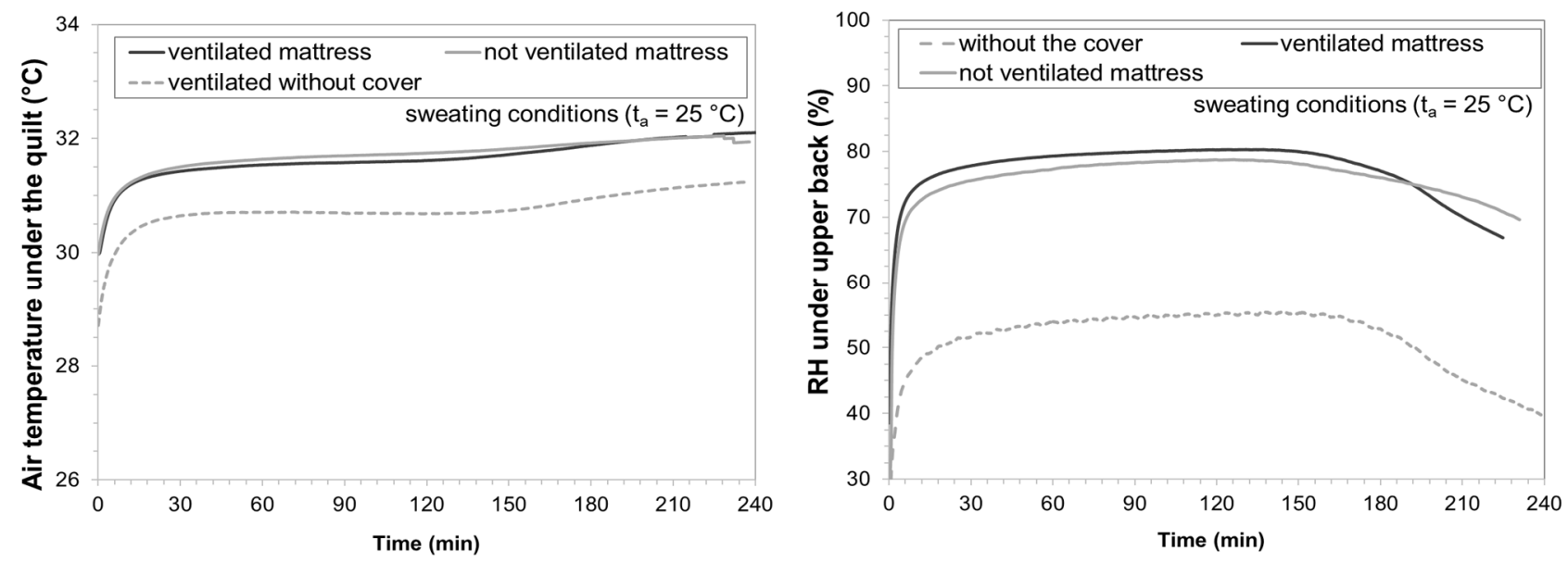

Fig. 5. a) Air temperature under the quilt $t_{a g}$ under sweating conditions, $t_{a}=25^{\circ} \mathrm{C}$. b) Average RH measured under the upper back, with RH sensors placed on top of the cloth and attached to the manikin, $t_{a}=25^{\circ} \mathrm{C}$.

A cooling effect of the ventilated mattress was expected especially under the sweating conditions, since evaporation of sweat cools down the body. Since the wet cloth was positioned under the back, only the heat loss readings from the back segment were analysed.

Figure $4 \mathrm{~b}$ presents average results of the heat power to the manikin's back $\left(P_{m b}\right)$ obtained under $t_{a}$ of $25^{\circ} \mathrm{C}$. Higher power supply indicates more cooling of the segment. Comparing ventilated and not ventilated mattress with its cover, it is seen that there was a fractional difference. The ventilated mattress provided on average maximum $2,0 \mathrm{~W} / \mathrm{m}^{2}$ more cooling. Moreover, after 4 hours, the readings merged to one level.

The results from the average heat loss of the back obtained with the ventilated mattress without textile cover had a different tendency, as shown in Fig. 4b. During the first 2,5 hours it provided cooling to the back segment, up to $10,0 \mathrm{~W} / \mathrm{m}^{2}$ more than the mattress with the textile cover. After this time, the $P_{m b}$ dropped down and eventually reached the same level as the mattress with the textile cover. This was caused by drying up of the cloth, when the moisture did not provide cooling to the back segment anymore. Moreover, the dry cloth eventually worked as a textile cover that created a resistance to possible natural ventilation. Hence, $P_{m b}$ dropped down to the same level as the mattress with the original textile cover.

Cooling provided by the mattress was generally smaller at $t_{a}$ of $28^{\circ} \mathrm{C}$, even though the difference between cooling by ventilated and not ventilated mattress was also up to $10 \mathrm{~W} / \mathrm{m}^{2}$.

With respect to natural body shape, the upper back in supine position is fully in contact with the mattress, in contrast to the lower back that creates a small gap between the body surface and the mattress. Measuring of the RH under the back was thus divided into 2 parts - upper (points 5, 6, and 7) and lower back (point 8), see Figure 2.

Rapid increase of the $\mathrm{RH}$ in the beginning of the measurements was caused by placing the wet cloth under the back segment. After reaching a certain level, the RH was kept at almost the same level and eventually started decreasing as the cloth dried up, as shown in Figure 5 b. Except for the case with the ventilated mattress without textile cover, RH levels were similar for upper and lower back, being in the range of $75 \%$ to $85 \%$. The ventilated mattress without textile cover showed considerably lower RH under the upper back. Nevertheless, this phenomenon must be verified by repeating the measurements.

\subsection{Impact of the original textile cover}

The porous mattress was provided with a textile cover from the manufacturer. While blocking the ventilation through the mattress, the blocking effect of the textile cover on the ventilation air flow and thermal insulation of the ventilated mattress was considered. This issue was investigated by performing four measurements under dry conditions at $t_{a}$ of $25{ }^{\circ} \mathrm{C}$, see the conditions and resulting $P_{m b}$ in Table 2.

The difference of the power supply between the not ventilated mattress with and without the textile cover was $15,0 \mathrm{~W} / \mathrm{m}^{2}$, which indicated impact of thermal insulation provided by the cover. In other words, the textile cover reduced the cooling by $15,0 \mathrm{~W} / \mathrm{m}^{2}$. For the mattress without the textile cover, ventilated and not ventilated, the difference was $8,5 \mathrm{~W} / \mathrm{m}^{2}$. This cooling was provided through the pure porous material. The cooling provided

Table 2. Average heat power supply to the manikin's back segment, under dry conditions, $t_{a}=25^{\circ} \mathrm{C}$.

\begin{tabular}{|c|c|c|c|}
\hline $\begin{array}{l}\text { ventilated } \\
\text { with cover }\end{array}$ & $\begin{array}{l}\text { not ventilated } \\
\text { with cover }\end{array}$ & $\begin{array}{c}\text { ventilated } \\
\text { without cover }\end{array}$ & $\begin{array}{l}\text { not ventilated } \\
\text { without cover }\end{array}$ \\
\hline
\end{tabular}

$\begin{array}{lllll}\text { Heat power supply }\left(\mathrm{W} / \mathrm{m}^{2}\right) & 17,2 & 13,9 & 37,4 & 28,9\end{array}$


through the porous mattress as with the cover increased with only $3,3 \mathrm{~W} / \mathrm{m}^{2}$. The porous material itself gave considerable cooling compared to the not ventilated mattress, however normal usage including textile cover offers fractional cooling effect to the back of the body.

\section{Discussion}

The measurements with the porous mattress showed that there is no significant benefit on the dry heat loss from the thermal manikin. The mattress showed more promising effects under wet conditions.

The obtained results showed a tendency of cooling provided by the porous mattress under specific conditions. The porous material showed considerable potential for bed micro-environment improvement, providing a passive way of cooling the back part of a body. However, there are several issues to be discussed and improved. The textile cover of the mattress created a barrier blocking most of the effect and reduced the cooling effect by working as a thermal insulator. The difference between the performance of the ventilated and not ventilated mattress, both with the cover, was small. However, more experimental repetitions should be performed to confirm this finding. Several experiments with the pure porous mattress without the cover and a common thin cotton bed sheet were performed to clarify the impact of another type of textile barrier on the performance. Tests showed nearly the same results for the mattress with the thin cotton bed sheet and mattress with its original textile cover. This result indicated possible further issues with using bed sheets together with the porous mattress, as it is common in most households.

It is also important to consider the intended use of this porous mattress. The tested sample was a $50 \mathrm{~mm}$ thick porous mattress, which might be intended as a top layer on a regular, thicker mattress. This regular mattress would prevent any kind of natural ventilation, since there would be basically no air flowing through. Same can be said for using a bed frame with a board instead of a grid, or a bed with a storage space underneath it. It is assumed that these conditions would eliminate any natural ventilation effect. In case of manufacturing a regular thick mattress out of this porous breathable material, further investigation would be needed to verify the impact of the mattress thickness on performed ventilation.

It is important to point out that the simple method used for simulating sweating has limitations and must be improved. The biggest issue was the cotton cloth, namely adjusting its temperature and wetness uniformity. To study the humidity conditions under the back in more detail, more RH sensors should be used. Furthermore, the measuring time for sweating condition must be prolonged to observe the entire transient process.

\section{Conclusion}

The studied mattress did not show any substantial improvement of the bed micro-climate under the dry conditions. Air temperature in the gap under the quilt was not changed evidently, except the space around the ankles.
Without sweating, prospective cooling of the body or any local parts was not observed.

No substantial effect was found regarding air temperature and relative humidity in the bed when the mattress was used together with a textile cover. The results showed only fractional cooling effect on the sweating back of the manikin at $t_{a}$ of $25^{\circ} \mathrm{C}$, when the mattress was used with the textile cover. However, the cooling effect increased when the mattress was used without the cover.

The impact of bedding was tested by using the porous mattress with a thin cotton bed sheet instead of the textile cover. The results indicated that even a thin bed sheet eliminated the prospective cooling effect of the mattress.

1. R. Raymann, D. Swaab, and E. Van Someren. Cutaneous warming promotes sleep onset. Am. J. Physiol., 288 (2005)

2. Y. Wang, Y. Liu, C. Song, and J. Liu. Appropriate indoor operative temperature and bedding microclimate temperature that satisfies the requirements of sleep thermal comfort. Building and Environment, 91:20-29 (2015)

3. L. Lan, Z. Lian, and Y. Lin. (2016). Comfortably cool bedroom environment and sleep quality. Building and Environment, 99:252-259 (2016)

4. L. Lan, L. Pan, Z. Lian, H. Huang, and Y. Lin. Experimental study on thermal comfort of sleeping people at different air temperatures. Building and Environment, 73:24-31 (2015)

5. K. Okamoto-Mizuno, K. Tsuzuki, K. Mizuno, and T. Iwaki. Effects of partial humid heat exposure during different segments of sleep on human stages and body temperature. Physiology and Behaviour, 83:759-765 (2005)

6. F. Rohles, and D. Munson. Sleep and the sleep environment temperature. Journal of Environmental Psychology, 1:207-214 (1981)

7. D. Wang, P. Chen, Y. Liu, C. Wu, and J. Liu. (2017) Heat transfer characteristics of a novel sleeping bed with an integrated hot water heating system. Applied Thermal Engineering, 113:79-86 (2017)

8. A. Melikov, Y. Li, E. Georgiev, and J. Wu. Bed microenvironment in hospital patient rooms with natural or mechanical ventilation. Proceedings of Healthy Buildings (2012)

9. Y. Hibino, S. Hokoi, K. Yoshida, S. Takada, M. Nakajima, and M. Yamate. Thermal physiological response to local heating and cooling during sleep. Frontiers of Architectural Research, 1:51-57 (2012)

10. M. Bivolarova, A. Melikov, C. Mizutani, K. Kajiwara, and Z. Bolashikov. (2016). Bed-integrated local exhaust ventilation system combined with local air 
cleaning for improved IAQ in hospital patient rooms. Building and Environment, 100:10-18 (2016)

11. Z. Lin, and S. Deng. A study on the thermal comfort in sleeping environment in the subtropics - measuring the total insulation values for the bedding systems commonly used in the subtropics. Building and Environment, 43:905-916 (2008)

12. Sensirion. The sensor company. Retrieved from https://www.sensirion.com/ (2018) 